\title{
EVALUATION OF TRMM-3B42V7 AND PERSIANN-CDR DAILY-PRECIPITATION PRODUCTS FOR THE SOUTHERN SLOPES OF ALBORZ MOUNTAINS, IRAN
}

\author{
Shahram Khalighi-Sigaroodi ${ }^{1} *$, Esmatullah Ghaljaee ${ }^{1}$, Alireza Moghaddam Nia ${ }^{1}$, Arash Malekian ${ }^{1}$, Fan Zhang ${ }^{2}$ \\ ${ }^{1}$ Faculty of Natural Resources, University of Tehran, Karaj, Iran - (khalighi, ghaljaee, moghaddamnia, malekian)@ut.ac.ir \\ ${ }^{2}$ Institute of Tibetan Plateau Research, Chinese Academy of Sciences - zhangfan@itpcas.ac.cn
}

KEY WORDS: Precipitation, Error assessment, TRMM-3B42 V7, PERSIANN-CDR, Southern slopes of Alborz mountains of Iran

\begin{abstract}
:
The density of rain gauges in many regions is lower than standard. Therefore, there are no precise estimates of precipitation in such regions. Today the use of satellite data to overcome this deficiency is increasing day to day. Unfortunately, the results from different satellite products also show a significant difference. Hence, their evaluation and validation are very important. The main objective of this study is to investigate the accuracy of the daily precipitation data of TRMM-3B42 V7 and PERSIANN-CDR satellites under a case study in the southern slopes of Alborz mountains, Iran. For this purpose, satellite precipitation data were compared with ground measured precipitation data of 12 synoptic stations over a 15- year period. The statistical criteria of MAE, RMSE, and Bias were used to assess error and the statistical indices of POD, FAR, and CSI was used to evaluate the recognition rate of occurrence or nonoccurrence of precipitation. The results showed that there is a low correlation between satellite precipitation data and ground measured precipitation data, and the lowest and the highest values of correlation coefficient are from 0.228 to 0.402 for TRMM and from 0.047 to 0.427 for PERSIANN, respectively. However, there is a theoretical consensus on other assessment parameters, so that TRMM data is preferable in terms of the amount of data bias and the False Alarm Ratio (FAR) and PERSIANN data is superior in terms of RMSE, POD, and CSI. Also, it seems that in the study region, both of TRMM and PERSIANN have overestimated the number of daily precipitation events, so that the number of daily precipitation events was estimated about $125 \%$ and $200 \%$ of ground stations by TRMM and PERSIANN, respectively.
\end{abstract}

\section{INTRODUCTION}

rainfall is one of the greatest inputs of hydrological and vegetative models (Sorooshian et al., 2011). Two important issues, exclusively in hydro-meteorological studies, are the possible sparsity of data sampling points (gauge stations), and the discontinuities in the data and the quality of the temporal records. These issues are seen in high altitude mountains because very heavy environments for precipitation measurements using remote sensing or traditional methods are due to difficult topography and climatic conditions and very variable weather conditions. (Scheel et al., 2011; Chen et al., 2011; Kashani et al., 2012). The lack of reliable and complete data is one of the most important challenging issues in rainfall analysis, hydrological forecasting and water resources management (Moazami et al., 2013). Over the past decades, frequent and severe droughts around the world have caused environmental, agricultural and financial losses. (Piao et al., 2010; Wang et al., 2018). Due to the lack of rainfall data, it has caused problems in estimating and predicting droughts. In Iran, rainfall data is limited in many regions. To overcome this limitation, we can use spatial interpolation methods, statistical regression and rainfall estimation algorithms using satellite imagery. The error of the interpolation methods in high mountainous regions and arid and semi-arid regions is very high. Hence, in the last two decades, many studies have been carried out on development of different methods for measuring it using satellite imagery in order to enhance the accuracy and precision of rainfall estimated in regions without complete and reliable records (Moazami et al., 2016). PERSIANN (Precipitation Estimation from Remotely Sensed Information using Artificial Neural Networks), TRMM
(The Tropical Rainfall Measuring Mission), CMORPH (Climate Prediction centre Morphing technique), and APHRODITE (Asian Precipitation - Highly-Resolved Observational Data Integration towards Evaluation), GPCC (Global Precipitation Climatology Centre) algorithms are among the sources that can be used to estimate rainfall. PERSIANN-Climate data recording (PERSIANN-CDR) data (Ashouri et al., 2015) and Climate Hazards Group (CHG) InfraRed Precipitation with Station data (CHIRPS) (Funk et al., 2015) are the most famous long-term Satellite Rainfall Estimates (SREs) with records of more than 30 years and therefore suitable for drought monitoring and other weather applications. The performance of both products has been widely investigated and confirmed in various studies, including precision analysis (Ward et al., 2011; Katsanos et al., 2016; Zambrano et al., 2016; Alijanian et al., 2017; Baez-Villanueva et al., 2018; Gao et al., 2018; Hussain et al., 2018; Tan and Santo, 2018), performance in extreme weather conditions (Miao et al., 2015; Katiraie-Boroujerdy et al.,2017), hydrologic modeling (Tuo et al., 2016;Zhu et al., 2016; Poméon et al. ,2017).

The PERSIANN-CDR and TRMM-3B42 algorithms with a spatial resolution of 0.25 degree provide precipitation data with temporal resolutions of 30 minutes and 3 hours, respectively. The CMORPH algorithm has a spatial resolution of 0.07 degrees and a temporal resolution of 30 minutes (Qin, et al., 2014; Ghajarnia et al., 2015). Nevertheless, owing to the indirect nature of satellite precipitation estimates, it is essential to evaluate these estimates against the measurements of ground stations prior to application to hydrological operations at daily and sub-daily scales (Jiang et al., 2012; Moazami et al., 2013).

\footnotetext{
* Corresponding author
} 
Many studies have been carried out worldwide and in Iran, some of which are referred to below. Javanmard et al. (2010) evaluated the precipitation estimates of TRMM-3B42 V6 in Iran. The obtained results of this research showed that version 6 of the TRMM-3B 42 product underestimates about $25 \%$ of the average annual precipitation of the whole country (about $0.17 \mathrm{~mm}$ per day) (Javanmard et al. 2010).

A number of researches have been carried out in the field of satellite precipitation assessment. Some of these researches are briefly mentioned below. Hughes (2006) compared the PERSIANN satellite data and the Global Precipitation Climatology Project (GPCP), with available data for the rain gauge stations located in four basins in the southern Africa region. Hong et al. (2007) compared hourly and daily precipitation estimates from PERSIANN in warm seasons with precipitation measurements by rain gauge stations in the northwestern region of Mexico. The results of their research indicate that the PERSIANN generally captures the spatial distribution and timing of daily convective precipitation in the study region. Kizza et al. (2012) estimated the areal precipitation over Lake Victoria by TRMM 3B43 and PERSIANN products. The results of their study show that TRMM-3B42 has more bias (mean differences) than PERSIANN, but its correlation of within-year changes was better. Chen et al. (2013) evaluated the estimates of tropical storm daily precipitation using TRMM-3B42 Version 7. In this study, the Pacific Precipitation (PACRAIN) data were used as a reference for evaluating TRMM-3B42 information. The results of this study show that 42TRMM-3B correlates well with observational data.

Milewski et al. (2015) assessed the accuracies of the different versions of TRMM Multi-satellite Precipitation Analysis (TMPA) products (3B42: V6, V7temp, V7, RTV7) against 125 rain gauges in Northern Morocco under different climatic and topographic conditions. The results of their study showed the newest algorithm development (3B42 V7) outperforms the previous version (3B42 V6), especially in regions with low precipitation and high altitude.

Given the importance of precipitation data, its precise estimation has always been a challenging issue in areas where rain gauge network density is not sufficient, or impassable (out of regular access) areas are nonexistence of any rain gauge. Therefore, the use of satellite data is one of the leading strategies for obtaining precipitation data in these areas. However, the accuracy of satellite precipitation data are different from one region to another and is not completely accurate. Therefore, in such a situation, the study of the accuracy of satellite precipitation data in different regions is one of the research needs.

Therefore, in the present paper, the main objective is to investigate the accuracies of the precipitation data of the two satellite databases of PERSIANN and TRMM-3B42 V7 in the southern slopes of Alborz Mountains, with the largest and most densely populated cities in Iran.

\section{DETAILS EXPERIMENTAL}

\subsection{Materials and Methodology}

In this study, two precipitation data sets for the period of 20002015 were used: (1) Daily observation data of the stations under study in the southern Alborz area; (2) Daily precipitation data of PERSIANN and TRMM-3B42 version 7. Satellite precipitation data includes a network of grids with a distance of $0.25^{\circ}$. It should be noted that for Iran's latitudes, 0.25 degrees is equal to $27.8 \mathrm{~km}$, while for different geographical latitudes, this value ranges from $22.22 \mathrm{~km}$ in the northern hemisphere and southern hemisphere to $27.8 \mathrm{~km}$ in the equator. Figure (1) shows the location of rain gauge stations and corresponding networks.

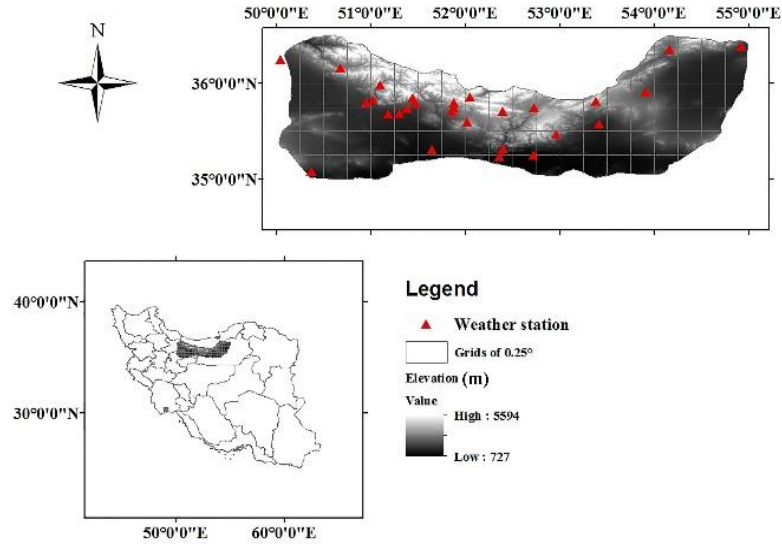

Figure 1. Location, rain gauge stations, topographic characteristics and elevation $(\mathrm{m})$ of the study area

Four statistical criteria of mean differences (Bias), mean absolute error (MAE), root mean square error (RMSE) and correlation coefficient (R) were employed to assess the accuracy of satellite precipitation data. Table 1 represents a list of statistical criteria used in this study. According to this table, PSi denotes the amount of satellite precipitation in the i-th time step, POi denotes the observed precipitation in the i-th step, $\mathrm{N}$ is the number of precipitation data, PS denotes the average amount of satellite precipitation per pixel and $\mathrm{PO}$ denotes the average precipitation in rain gauge stations. It is obvious that the high PCC content and the low values of RMSE and MAE show the high accuracy of estimates. Also, negative and positive values of Bias represent a relatively low estimation and a relatively high estimation of satellite data, respectively.

Also, three statistical classification indices of the probability of detection (POD), FAR (False alarm ratio) and CSI (Critical success index) were used to evaluate the detection of precipitation by the algorithms used in this study (Wilks, 2011). The POD index represents the ratio of the correct identification of satellite precipitation to the total number of occurrences recorded in rain gauge stations. The FAR index represents ratio of cases where satellite data indicate rain while rain gauge data do not. The CSI index indicates the ratio that the occurrence of precipitation is properly identified by the satellite (Moazami, Golian, et al. 2016), as given in Table 1.

\section{RESULTS AND DISCUSSION}

In this research, error analysis of multi-satellite precipitation estimates was conducted with an independent rain gauge network under a study area. The statistics for the daily precipitation events of the entire period, is shown in figure (2), in both satellite products (CDR and 3B42). The values of MAE, RMSE and Bias, $\mathrm{R}$ correlation coefficient, $\mathrm{R}^{2}$ explanatory factor, and validation indices (POD, FAR, CSI) on a daily scale indicate the relative superiority of PERSIANN-CDR on TRMM in terms of better RMSE, R and POD values, CSI and suggests that PERSIANN algorithm estimates the wet and dry days better than TRMM. The obtained results from this study conform with the research findings of Zhong et al. (2019), which was done throughout the whole of China, that found similar results on the use of the PERSIANN-CDR and TRMM-3B4 v7 in detecting wet and dry days in the long-term studies of PERSIANN-CDR. 


\begin{tabular}{|c|l|c|}
\hline Statistic metric & Equation & $\begin{array}{c}\text { Perfect } \\
\text { value }\end{array}$ \\
\hline $\begin{array}{c}\text { Correlation } \\
\text { coefficient (R) }\end{array}$ & $R=\frac{\sum\left(P S_{i}-\overline{P S_{l}}\right)\left(P O_{i}-\overline{P O_{l}}\right)}{\sqrt{\sum\left(P S_{i}-\overline{P S_{l}}\right)^{2} \sum\left(P O_{i}-\overline{P O_{l}}\right)^{2}}}$ & 1 \\
\hline $\begin{array}{c}\text { Mean absolute } \\
\text { error (MAE) }\end{array}$ & $M A E=\frac{\sum\left|P S_{i}-P O_{i}\right|}{N}$ & 0 \\
\hline Bias & Bias $=\frac{\sum\left(P S_{i}-P O_{i}\right)}{N}$ & 0 \\
\hline $\begin{array}{c}\text { Root mean } \\
\text { squared error } \\
\text { (RMSE) }\end{array}$ & $R M S E=\left[\frac{\sum\left(P S_{i}-P O_{i}\right)^{2}}{N}\right]^{\frac{1}{2}}$ & 1 \\
\hline $\begin{array}{c}\text { The probability } \\
\text { of detection } \\
\text { (POD) }\end{array}$ & $P O D=\frac{\text { Hits }}{\text { Hits }+ \text { Misses }}$ & 1 \\
\hline $\begin{array}{c}\text { False alarm } \\
\text { ratio (FAR) }\end{array}$ & FAR $=\frac{\text { False Alarms }}{\text { Hits }+ \text { False Alarms }}$ & 0 \\
\hline $\begin{array}{c}\text { Critical success } \\
\text { index (CSI) }\end{array}$ & CSI $=\frac{\text { Hits }}{\text { Hits }+ \text { Misses }+ \text { Falses }}$ & \\
\hline
\end{tabular}

Table 1. Statistical List of Criteria Used for Comparison and Statistical Evaluation

Based on the results of the present study, the amounts of Bias and the FAR for the TRMM daily precipitation data were lower, indicating better performance of the TRMM. In addition, according to Gao et al. (2018), TRMM estimates have a lower bias than PERSIANN estimates; it highlights the fact that TRMM daily estimates have closest to ground stations. It was also found that in the study region, both of TRMM and PERSIANN have overestimated the number of daily rainfall events, so that the number of daily rainfall events were estimated about $125 \%$ and $200 \%$ of ground stations by TRMM and PERSIANN, respectively.

As can be seen from figure 2, the highest correlation values are between daily data of Qazvin station and PERSIANN and TRMM estimates with correlation coefficients of 0.42 and 0.4 , respectively. Therefore, it can be said that the correlation coefficient on the daily scale is significant at $1 \%$ level, which conforms to the results of other researches (e.g. Almazroui, 2011; Sharma et al., 2003; Sorooshian, et al., 2000). In addition, at high altitudes, which are usually snow-covered, such as the Abali and Firuzkuh (Gaw) stations, the amount of data bias is negative, indicating precipitation underestimation at high altitudes, often in snowy cold seasons. At this time, microwave and infrared sensors do not fully detect precipitation that indicates massive convective forces affect rainfall estimation. It was found by McCollum et al. (2002) that the microwave algorithm estimates rainfall over summer and tends to underestimation in the winter months. The results obtained from this study conform to that of Javanmard et al. (2010), citing the underestimation of satellite rainfall attitudes. The three indicators of POD, FAR and CSI were calculated based on the daily data set for the whole period. The results show that PERSIANN-CDR satellite data in most stations (Semnan, Karaj, Qazvin, Garmsar, Tehran Meherabad and Shemiran airports) estimated rainy days by more than 80 percent while it is much lower in TRMM-3B42-v7. Also, FAR value for TRMM is less, so the number of missed rainfall alerts is lower, as a result, estimated PERSIANN wet days and TRMM better dry days.

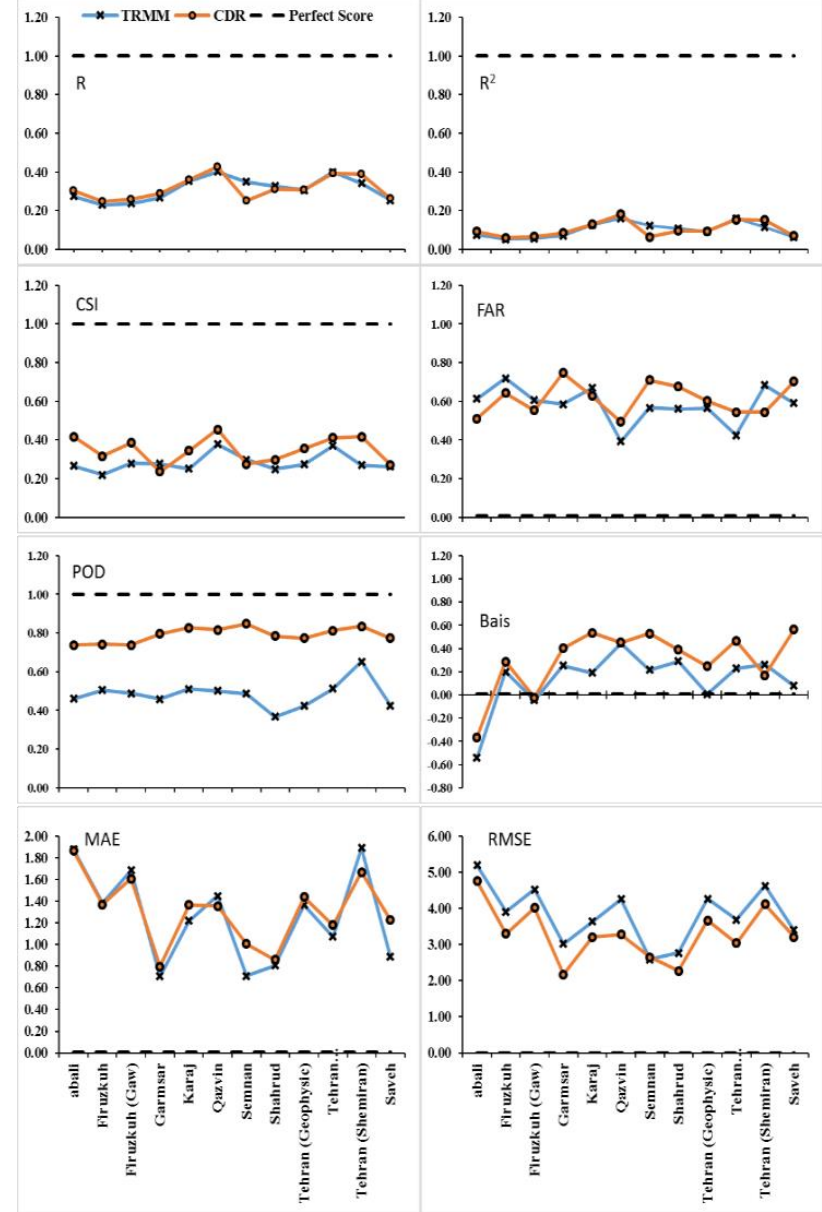

Figure 2. Daily precipitation statistics for each satellite product (CDR and 3B42)

\section{CONCLUSIONS}

Reliable precipitation estimate is one of the most important needs in water resources management. However, in many parts of the world, especially Iran, there is a tangible lack of time and space for rainfall data. Therefore, the use of satellite data is one of the key strategies. The results of the comparison of the performances of the two rainfall bases showed that their accuracy depends on the time and space scales.

\section{REFERENCES}

Alijanian, M., Rakhshandehroo, G. R., Mishra, A. K., \& Dehghani, M. (2017). Evaluation of satellite rainfall climatology using CMORPH, PERSIANN-CDR, PERSIANN, TRMM, MSWEP over Iran. International Journal of Climatology, 37(14), 4896-4914.

Almazroui, M. (2011). Calibration of TRMM rainfall climatology over Saudi Arabia during 1998-2009. Atmospheric Research, 99(3-4), 400-414.

Ashouri, H., Hsu, K. L., Sorooshian, S., Braithwaite, D. K., Knapp, K. R., Cecil, L. D. \& Prat, O. P. (2015). PERSIANNCDR: Daily precipitation climate data record from multisatellite observations for hydrological and climate studies. Bulletin of the American Meteorological Society, 96(1), 69-83. 
Baez-Villanueva, O. M., Zambrano-Bigiarini, M., Ribbe, L., Nauditt, A., Giraldo-Osorio, J. D., \& Thinh, N. X. (2018). Temporal and spatial evaluation of satellite rainfall estimates over different regions in Latin-America. Atmospheric research, $213,34-50$.

Chen, F., Yuan, Y. J., \& Wei, W. (2011). Climatic response of Picea crassifolia tree-ring parameters and precipitation reconstruction in the western Qilian Mountains, China. Journal of Arid Environments, 75(11), 1121-1128.

Chen, Y., Ebert, E. E., Walsh, K. J., \& Davidson, N. E. (2013). Evaluation of TRMM 3B42 precipitation estimates of tropical cyclone rainfall using PACRAIN data. Journal of Geophysical Research: Atmospheres, 118(5), 2184-2196.

Funk, C., Peterson, P., Landsfeld, M., Pedreros, D., Verdin, J., Shukla, S., ... \& Michaelsen, J. (2015). The climate hazards infrared precipitation with stations - a new environmental record for monitoring extremes. Scientific data, 2, 150066.

Gao, F., Zhang, Y., Chen, Q., Wang, P., Yang, H., Yao, Y., \& Cai, W. (2018). Comparison of two long-term and highresolution satellite precipitation datasets in Xinjiang, China. Atmospheric research, 212, 150-157.

Gao, X., Zhu, Q., Yang, Z., \& Wang, H. (2018). Evaluation and hydrological application of CMADS against TRMM 3B42V7, PERSIANN-CDR, NCEP-CFSR, and Gauge-Based Datasets in Xiang River Basin of China. Water, 10(9), 1225.

Ghajarnia, N., Liaghat, A., \& Arasteh, P. D. (2015). Comparison and evaluation of high resolution precipitation estimation products in Urmia Basin-Iran. Atmospheric Research, 158, 5065 .

Hong, Y., Gochis, D., Cheng, J. T., Hsu, K. L., \& Sorooshian, S. (2007). Evaluation of PERSIANN-CCS rainfall measurement using the NAME event rain gauge network. Journal of Hydrometeorology, 8(3), 469-482.

Hughes, D. A. (2006). Comparison of satellite rainfall data with observations from gauging station networks. Journal of Hydrology, 327(3-4), 399-410.

Hussain, Y., Satgé, F., Hussain, M. B., Martinez-Carvajal, H., Bonnet, M. P., Cárdenas-Soto, M., ... \& Akhter, G. (2018). Performance of CMORPH, TMPA, and PERSIANN rainfall datasets over plain, mountainous, and glacial regions of Pakistan. Theoretical and applied climatology, 131(3-4), 1119-1132.

Javanmard, S., Yatagai, A., Nodzu, M. I., BodaghJamali, J., \& Kawamoto, H. (2010). Comparing high-resolution gridded precipitation data with satellite rainfall estimates of TRMM_3B42 over Iran. Advances in Geosciences, 25, 119-125.

Jiang, S., L. Ren, Y. Hong, B. Yong, X. Yang, F. Yuan, and M. Ma. (2012). Comprehensive Evaluation of Multi-Satellite Precipitation Products with a Dense Rain Gauge Network and Optimally Merging Their Simulated Hydrological Flows Using the Bayesian Model Averaging Method. Journal of Hydrology 452-453: 213-225.

Kashani, M. H. \& Dinpashoh, Y. (2012). Evaluation of efficiency of different estimation methods for missing climatological data. Stochastic environmental research and risk assessment, 26(1), 59-71.
Katiraie-Boroujerdy, P. S., Asanjan, A. A., Hsu, K. L., \& Sorooshian, S. (2017). Intercomparison of PERSIANN-CDR and TRMM-3B42V7 precipitation estimates at monthly and daily time scales. Atmospheric Research, 193, 36-49.

Katsanos, D., Retalis, A., \& Michaelides, S. (2016). Validation of a high-resolution precipitation database (CHIRPS) over Cyprus for a 30-year period. Atmospheric research, 169, 459464.

Kizza, M., Westerberg, I., Rodhe, A., \& Ntale, H. K. (2012). Estimating areal rainfall over Lake Victoria and its basin using ground-based and satellite data. Journal of Hydrology, 464, 401411 .

Kottegoda, N. T., \& Rosso, R. (2008). Applied statistics for civil and environmental engineers. Malden, MA: Blackwell.

Milewski, A., Elkadiri, R., \& Durham, M. (2015). Assessment and comparison of TMPA satellite precipitation products in varying climatic and topographic regimes in Morocco. Remote Sensing, 7(5), 5697-5717.

Moazami, S., Golian, S., Hong, Y., Sheng, C., \& Kavianpour, M. R. (2016). Comprehensive evaluation of four high-resolution satellite precipitation products under diverse climate conditions in Iran. Hydrological Sciences Journal, 61(2), 420-440.

Moazami, S., Golian, S., Kavianpour, M. R. \& Hong, Y. (2013). Comparison of PERSIANN and V7 TRMM Multi-satellite Precipitation Analysis (TMPA) products with rain gauge data over Iran. International journal of remote sensing, 34(22), 81568171.

Piao S, Ciais P, Huang Y, Shen Z, Peng S, Li J, Zhou L, Liu,H, Ma Y, Ding Y, Friedlingstein P, Liu C, Tan K, Yu Y,Zhang T, Fang J, (2010). The impacts of climate change on water resources and agriculture in China. Nature, 467, 43-51.

Poméon, T., Jackisch, D., \& Diekkrüger, B. (2017). Evaluating the performance of remotely sensed and reanalysed precipitation data over West Africa using HBV light. Journal of hydrology, $547,222-235$

Qin, Y., Chen, Z., Shen, Y., Zhang, S., \& Shi, R. (2014). Evaluation of satellite rainfall estimates over the Chinese Mainland. Remote Sensing, 6(11), 11649-11672.

Scheel, M. L. M., Rohrer, M., Huggel, C., Santos Villar, D., Silvestre, E., \& Huffman, G. J. (2011). Evaluation of TRMM Multi-satellite Precipitation Analysis (TMPA) performance in the Central Andes region and its dependency on spatial and temporal resolution. Hydrology and Earth System Sciences, 15(8), 2649-2663.

Sharma, S., Viswanathan, G., Rao, R., Sarma, D. K., \& Konwar, M. (2003). STUDY OF PRECIPITATING SYSTEMS BY DOPPLER WEATHER RADAR AND TROPICAL RAINFALL MEASURING MISSION PRECIPITATION RADAR. Department of Physics, Kohima Science College, Jotsoma, Kohima, Nagaland, India, 797-802.

Sorooshian, S., AghaKouchak, A., Arkin, P., Eylander, J., Foufoula-Georgiou, E., Harmon, R., ... \& Skofronick-Jackson, G. (2011). Advanced concepts on remote sensing of precipitation at multiple scales. Bulletin of the American Meteorological Society, 92(10), 1353-1357. 
Sorooshian, S., Hsu, K. L., Gao, X., Gupta, H. V., Imam, B., \& Braithwaite, D. (2000). Evaluation of PERSIANN system satellite-based estimates of tropical rainfall. Bulletin of the American Meteorological Society, 81(9), 2035-2046.

Tan, M. L., \& Santo, H. (2018). Comparison of GPM IMERG, TMPA 3B42 and PERSIANN-CDR satellite precipitation products over Malaysia. Atmospheric research, 202, 63-76.

Tuo, Y., Duan, Z., Disse, M., \& Chiogna, G. (2016). Evaluation of precipitation input for SWAT modeling in Alpine catchment: A case study in the Adige river basin (Italy). Science of the total environment, 573, 66-82.

Wang, Z., Zhong, R., Lai, C., Zeng, Z., Lian, Y., \& Bai, X. (2018). Climate change enhances the severity and variability of drought in the Pearl River Basin in South China in the 21st century. Agricultural and Forest Meteorology, 249, 149-162.

Ward, E., Buytaert, W., Peaver, L., \& Wheater, H. (2011). Evaluation of precipitation products over complex mountainous terrain: A water resources perspective. Advances in Water Resources, 34(10), 1222-1231.

Wilks, D. S. (2011). Cluster analysis. International geophysics, Elsevier. 100: 603-616.

Zambrano, F., Wardlow, B., \& Tadesse, T. (2016). Evaluating satellite-derived long-term historical precipitation datasets for drought monitoring in Chile. In Remote Sensing for Agriculture, Ecosystems, and Hydrology XVIII (Vol. 9998, p. 999823). International Society for Optics and Photonics.

Zhong, R., Chen, X., Lai, C., Wang, Z., Lian, Y., Yu, H., \& Wu, $X$. (2019). Drought monitoring utility of satellite-based precipitation products across mainland China. Journal of Hydrology, 568, 343-359.

Zhu, Q., Xuan, W., Liu, L., \& Xu, Y. P. (2016). Evaluation and hydrological application of precipitation estimates derived from PERSIANN-CDR, TRMM 3B42V7, and NCEP-CFSR over humid regions in China. Hydrological Processes, 30(17), 30613083. 